\title{
DOCUMENTING FOR POSTERITY: ADVOCATING THE USE OF ADVANCED RECORDING TECHNIQUES FOR DOCUMENTATION IN THE FIELD OF BUILDING ARCHAEOLOGY
}

\author{
P.J. De Vos ${ }^{1}$ \\ ${ }^{1}$ ELO, Erfgoed Leiden en Omstreken, 2311PZ Leiden, The Netherlands \\ pj.de.vos@erfgoedleiden.nl
}

Identifying heritage places for posterity and preparedness

KEY WORDS: Rapid documentation, building archaeology, automated photogrammetry, total station, orthoimage, Computer-Aided Drafting, education.

\begin{abstract}
:
Since the new millennium, living in historic cities has become extremely popular in the Netherlands. As a consequence, historic environments are being adapted to meet modern living standards. Houses are constantly subjected to development, restoration and renovation. Although most projects are carried out with great care and strive to preserve and respect as much historic material as possible, nevertheless a significant amount of historical fabric disappears. This puts enormous pressure on building archaeologists that struggle to rapidly and accurately capture in situ authentic material and historical evidence in the midst of construction works. In Leiden, a medieval city that flourished during the seventeenth century and that today counts over 3,000 listed monuments, a solution to the problem has been found with the implementation of advanced recording techniques. Since 2014, building archaeologists of the city council have experienced first-hand that new recording techniques, such as laser scanning and photogrammetry, have dramatically decreased time spent on site with documentation. Time they now use to uncover, analyse and interpret the recovered historical data. Nevertheless, within building archaeology education, a strong case is made for hand drawing as a method for understanding a building, emphasising the importance of close observation and physical contact with the subject. In this paper, the use of advanced recording techniques in building archaeology is being advocated, confronting traditional educational theory with practise, and research tradition with the rapid rise of new recording technologies.
\end{abstract}

\section{HISTORICAL CITIES AT RISK}

Cultural heritage in every part of the world is always in peril and demands constant vigilance and preparedness (Araoz, 2010). Not only heritage threatened with natural disasters or human conflicts, and not only monuments and sites presented in the ICOMOS World Reports on Monuments and Sites in Danger. The substantial impact of development pressures on the loss of authentic historical material is often overlooked. This assertion can be substantiated by taking as an example the historical city of Leiden in the Netherlands. A medieval city that flourished during the seventeenth century, the so called Dutch Golden Age, with over 3,000 listed monuments.

Built heritage in Dutch cities such as Leiden, Amsterdam, Haarlem and Utrecht is not directly recognised as being at risk or endangered. This because the Netherlands generally pursues a thorough monument regulation and an active protection program. In 'Preserving the world's great cities' by A.M. Tung, Amsterdam is even considered as an example that managed to stop the $20^{\text {th }}$ century "culture of destruction" at an early stage (Tung, 2001). Still however, on a daily basis enormous amounts of historical material disappear from the cities in the context of redevelopment, renovation, and restoration. Even in the bestbalanced conservative restoration projects, certain choices lead to the loss of authentic material.

This material is crucial for the work of building archaeologists. Building archaeology attempts to reconstruct the history of existing buildings, using direct observations of the building themselves. Building archaeologists identify and analyse materials, building techniques, continuousness and gaps, demolition tracks, the way a specific element is positioned to the next one, etc. In other words, based on significant traces, the study aims to reconstruct the passage of the monument throughout the different historical periods (Boato \& Pittaluga, 2000).

Building archaeology is devoted to the entire spectrum of construction, not only aesthetically outstanding monuments but also vernacular housing. Great temples, cathedrals and the palaces of the wealthy are of interest, as well as the cottages of the poor, military sites such as castles and city walls, and industrial structures from mills to dams and bridges are being researched (Schuller, 2002).

In the city of Leiden, monuments and buildings that have a core dating back to before 1850 are required to undergo archaeological research when owners apply for a building permit. The outcome of such research is taken into consideration when issuing a building permit.

In almost every building that is being researched, layers of different historic periods are discovered, dating from the middle ages up until recent times. For those not involved in the discipline of building archaeology this is often surprising. One must understand that in the past, architectural alterations often only added up to an existing structure or finishing, removing just a strict minimum of original material. This for the simple reason that material and labour was expensive. To keep costs as low as possible, houses were modernised by installing a new façade, whilst interiors were only altered in representative rooms and by reusing, covering or simply leaving in place the original building materials. 
This phenomenon of reusing or just leaving existing materials continued up until the post-war era, when material became cheaper and prefabricated building elements made their appearance. However in this post-war era, historical cities and their inhabitants remained poor. This continued until the 1980's when historical cities were still considered to be dying. They impoverished and ran empty (Marlet, 2015). For decades, the inner cities of Amsterdam, Haarlem, Utrecht, Leiden and other historic towns were subject to decay. Renovation works were often limited to the necessary patch works.

It is only since the new millennium that ideas about historical cities changed. Due to their unique character and intimate atmosphere, historical cities regained popularity (Figure 1). The new city dwellers are well educated and wealthy (Marlet, 2016a), whilst building materials are cheaper than ever before (Figure 2). This process of gentrification led to sky high housing prices, which put enormous pressure on historic urban structures. Built heritage in these areas became subjected to development, restoration and renovation. Patch works on mini budgets become big interventions with big budgets, modernising historical buildings to meet the standards of today, and even that of tomorrow, trying to implement many kinds of sustainability measures. Cities are forced to face the difficult challenge of adapting the historic environment to meet contemporary functions (Tung, 2001).

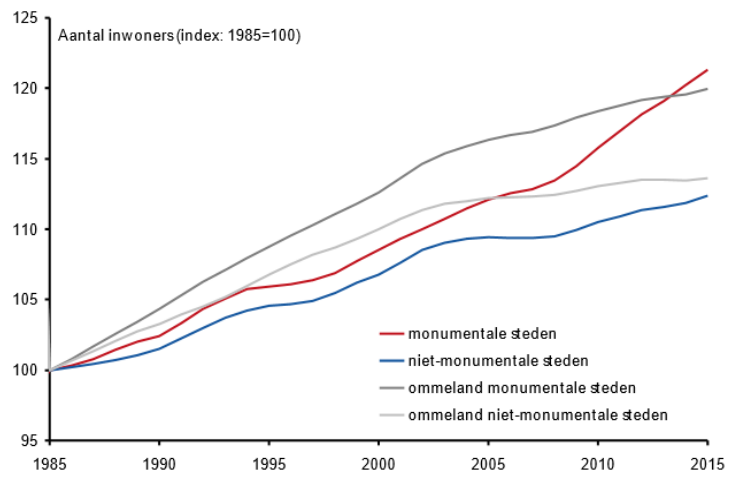

Figure 1. In red: number of inhabitants in monumental cities in the Netherlands. (Marlet, 2016a)

From the perspective of building archaeology, the impact on the historical material in the city is substantial. Within these new developments, historical houses are often being stripped down to the bare structures, removing different layers of past wall, floor, and ceiling finishing. Concerning the structures themselves, deteriorated elements get replaced, removing the authentic material. The materials being removed are not always (recognised as) of high value, but are crucial sources within the work of building archaeology.

Although most projects are carefully carried out with respect to the monument, striving to preserve as much as possible, not all historical elements can be saved. For this reason it is necessary to at least capture in situ authentic historical materials for posterity before they disappears. Also structures that do remain in situ, like floor constructions with traces of compartment walls, staircases, or walls with tracks of fireplaces, candle niches, etc. are only visible for a short period of time before they are covered by new interior finishes. Even applying new layers of paint or stucco means that valuable information about the construction of historical buildings can be removed.
Therefore, the goal is to completely record a three-dimensional object in its current state including all architectural alterations, deformations and structural detail (Schuller, 2002).

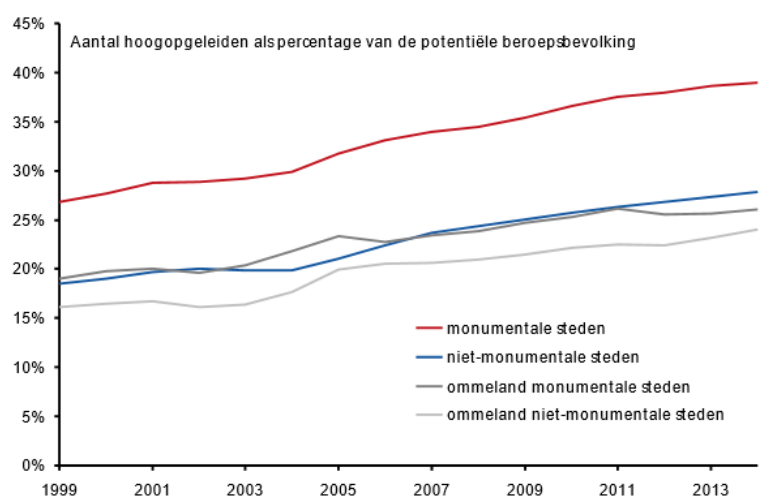

Figure 2. In red: number of highly educated people as a percentage of the potential labour force in historical cities in the Netherlands (Marlet, 2016a)

This task is ambitious, because deadlines are tight. After all, different historical layers and building traces are only found during restoration or renovation works. In the midst of building procedures, rapid on site documentation is crucial.

\section{TRADITIONAL DOCUMENTATION FOR BUILDING ARCHAEOLOGY}

The Charter of Venice for the Conservation and Restoration of Monuments and Sites states in Article 16 that "in all works of preservation, restoration or excavation, there should always be precise documentation in the form analytical and critical reports, illustrated with drawings and photographs..." (ICOMOS, 1964).

In the Convention of Sofia of 1996 that elaborated on Principles for the recording of monuments, groups of buildings and sites, the previous statement is specified, stating that: "Recording of the cultural heritage should be seen as a priority, and should be undertaken especially before, during and after any works of repair, alteration, or other intervention, and when evidence of its history is revealed during such works" (ICOMOS, 1996).

These conventions clearly stress the importance of documentation by building archaeologists. However, apart from the fact that documentation should be detailed, these conventions do not state what it is exactly that should be documented, neither do they state how documentation should take place.

\subsection{Level of accuracy}

In 2002 Manfred Schuller, a German scholar and pioneer in establishing the discipline of building archaeology in Europe, published Building Archaeology. In this essay issued by ICOMOS, he states the following concerning on-site documentation:

"The goal is to completely record a three-dimensional object in its current state (including all architectural alterations, deformations and structural details), true to scale, using dimensions that can be understood and reproduced. Extreme exactitude is necessary - in measurement and representation." (Schuller, 2002) 
In the widely used Recording, Documentation and Information Management for the Conservation of Heritage Places: Guiding Principles, written by Letellier in 2007 and published by the Getty Conservation Institute, a grid is published which indicates different levels of documentation. The grid describes a reconnaissance record, having low accuracy over a preliminary record to a detailed record having high accuracy (Figure 3).

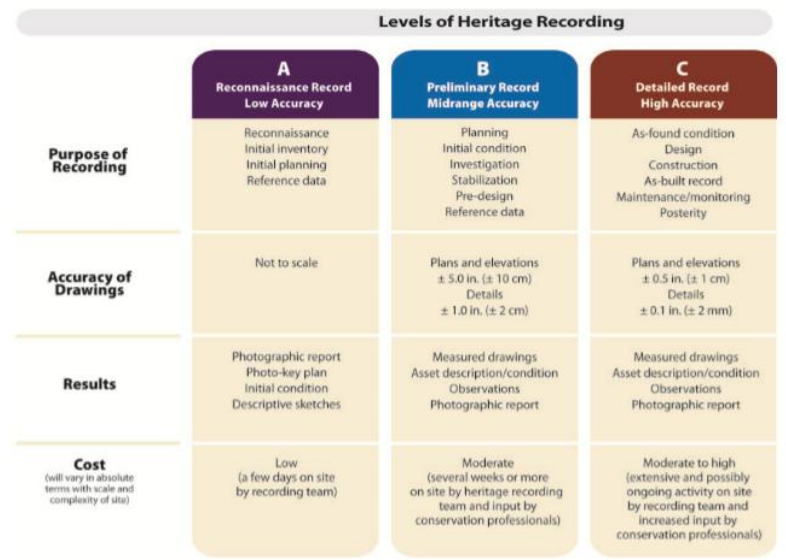

Figure 3. Levels of documentation A-rapid, B-detailed and C highly accurate. (Letellier, 2007)

From the above mentioned ICOMOS publications, it is clear that documentation should strive to achieve the creation of a detailed record having high accuracy. This includes measured drawings (details, plans and elevations), close observations and a photographic report (Figure 3).

However, as the writings of Letellier show, creating a detailed record also requires high costs, both in the sense of money and time. As seen in chapter one, for building archaeologists in cities as Leiden, Haarlem, Amsterdam and Utrecht, on site time is often valuable - for which rapid documentation is not a matter of choice, but a matter of absolute necessity.

Letellier endorses this. When discussing the grid, he mentions that it is important to link choice of time frame with choice of recording level and recording equipment. Some recording tools and technologies are inherently more rapid than others. The time and budget available for the work are key determinants in the choice of appropriate technologies (Letellier, 2007).

This brings us to the following questions regarding building documentation: How should be documented? Which equipment should be used? What is the correct methodology?

\subsection{Direct vs. indirect recording techniques}

Within the discipline of building archaeologists, a lot of attention is paid to drawing. Drawing is not just seen as a means of capturing historical objects, but rather as means of understanding them. Drawing is not only considered a recording method but a building archaeological research method. For this reason, within the discipline, a strong case is made for drawing by hand. In his publication Building Archaeology, Manfred Schuller, states the following:

"Measuring and drawing must always take place on site in a combined process. Only this approach sharpens the eye for critical observations. A purely mechanical survey of a building could be geodetically perfect in an ideal case, but it will always be incomplete as a record of the architectural reality." (Schuller, 2002)

He continues: "For the most important procedure, the precision work of drawing on site with first-hand observation and direct mapping of the findings, the ability and experience of the building archaeologist himself is the critical criterion. Machines cannot do this." (Schuller, 2002)

The usefulness of photogrammetry and photo rectification is recognised by Schuller only in rare exceptions for purposes of building archaeology. He explains: "The fundamental problem is that the analysis is separated from the object, so that one of the basic rules of building archaeology is not fulfilled, a violation that takes its revenge." (Schuller, 2002)

Although this publication is already 15 years old, ideas in the field of building archaeology have not much changed. In the Netherlands this criticism is repeated in current education of future building archaeologists. In the widely used handbook Inleiding in de bouwhistorie. Opmeten en onderzoeken van oude gebouwen for instance, CAD-drawings are considered "sterile" and hand drawing on site are necessity to get in touch with the buildings (Stenvert \& Van Tussenbroek, 2009). Although less bold, also in Drawing for Understanding, a recent publication of Historic England, a strong case is made on drawing by hand, repeating the connection between hand drawing, close observation, and thorough understanding of buildings:

"Drawing and measuring by hand remain useful tools for recording historic buildings. They are versatile methods, requiring close observation and physical contact with the subject, which can lead to additional discoveries and deepen understanding while conducting site work." (Adams, 2016)

From the perspective of the academic building archaeologist, it is obvious that drawing is a good discipline for developing information selection skills, for looking closely to the building and understanding anomalies. However, when the arguments are more deeply examined, it becomes clear that the above quoted publications do not prefer hand drawing itself, the preference goes for direct recording techniques over indirect recording techniques (RecorDIM, 2007).

When using direct techniques like Electronic Distance Measurement (EDM), GPS or hand drawing, selection and interpretation of data is made at the point of capture. This means that the expertise of the building archaeologist is decisive for the outcome of data collection. Because of on-site selection, direct techniques require heavy on site time.

Indirect techniques such as photogrammetry and laser scanning are largely free of data differentiation. Therefore they are fast on site. However they require near total coverage to be confident all the necessary details are captured. Selection and presentation of information is made in the post-capture phase, when the products of indirect techniques are processed, to line drawings or orthoimages in order to illustrate analyses or conclusions (RecorDIM, 2007).

When documenting, a well-balanced choice must be made based on time, money, equipment. Not the technique in itself is important. The chosen documentation technique must be able to meet the required information need within a certain time frame. Strategic use of both direct and indirect techniques will lead to efficient and as thorough as possible surveying, having a detailed as well as a rapid survey. 


\section{THE USE OF ADVANCED RECORDING TECHNIQUES IN BUILDING ARCHAEOLOGY}

The combined use of direct and indirect techniques for building documentation is brought into daily practice by the building archaeologists of Erfgoed Leiden en Omstreken, a municipal department for cultural heritage in the city of Leiden. On a yearly basis, they research between 80 to 100 historical buildings. Often this involves documentation in the middle of construction works, which - as described in the above - results in extremely tight deadlines. In the following, their methodology is described.

\subsection{Methodology for building documentation as practiced by Erfgoed Leiden}

As seen in the previous, it is important that the building archaeologist becomes familiar with the build structure, starting to thoroughly understand it. Close observation is key. Sometimes it involves additional dismantling. In this first stage, ideas and analyses are documented by field notes and sketches on paper. Sketches are also made on tablets (iPad Air 2) equipped with a drawing app (SketchbookX) and linked to a Wi-Fi-camera in order to make direct remarks on digital photographs.

In the second stage, a photographic documentation takes place, photographing both overviews and details. A full frame camera with a wide angle lens proves to work great in small rooms. In addition, each room is being photographed with a $360^{\circ}$ panorama camera (Ricoh Theta $S$ ). In the office, all photographs are described in Excel sheets. The metadata includes: address, date, photographer, interior or exterior, building volume, floor level, room description, position in the room, and description of the intent of the photo.

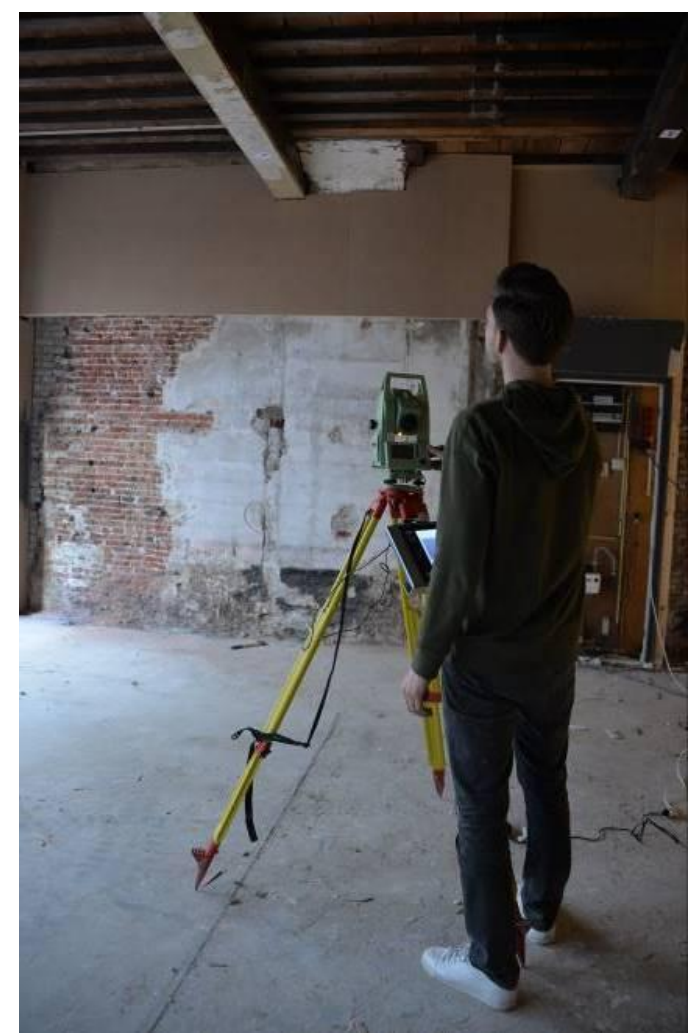

Figure 4. Recording targets with a Total Station connected to a tablet with BricsCAD to support the photogrammetric survey
In a third stage, a detailed documentation is carried out using both direct and indirect techniques. Basically, a combination of the following methods is used: hand measurements (using rulers, profile combs, digital distometers, etc.), REDM measurements (Using a Total Station, TheoLt and BricsCAD), and scaled-rectified Photography / SFM Photogrammetry for mapping ceilings, elevations and cross section elements.

The Total Station (Leica TPS800) is used to create general outlines of the buildings and to support scaled rectified photography and photogrammetry. It is connected to a Windows-based tablet PC running BricsCAD. The measurements collected by the Total Station are translated in BricsCAD commands using an off-the-shelf available software called TheoLT. One of the advantages of drawing directly in BricsCAD from the Total Station is the ability to immediately visualize the collected information.

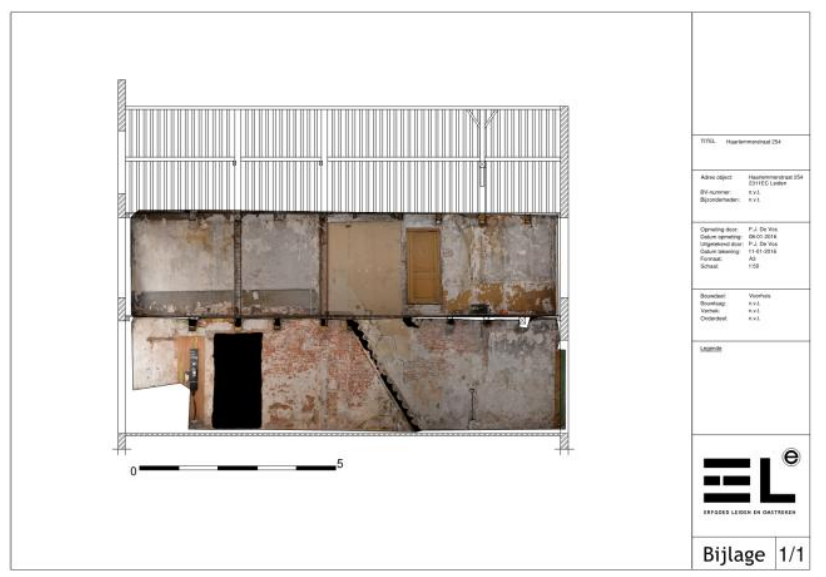

Figure 5. Section drawing of Haarlemmerstraat 254 in Leiden (dated 1409) based on architectural drawings and detailed hand measurements completed with orthophotos

With this setup, an outline of the walls of the rooms are drawn in plan section, when possible at approximately 1.5 meters height. After, also vertical sections are created. Features in the room, like stairs, floor height elevations, fireplaces and openings, are also measured from the position of the Total Station. The lines corresponding to different elements are divided into different layers in BricsCAD, such as plan, section, floor, fireplace, and targets.

The interior and the exterior, as well as different rooms on different floors, are connected by using a minimum of three targets per room. Closed traverse and network computation are only available in the TheoLt Pro version and therefore left aside.

The Total Station setup is also used in support of the photogrammetric record. Unique targets are recorded that are required to reference and scale the final photogrammetric model. The targets used are auto-generated and coming from the SFM photogrammetric software itself (Agisoft Photoscan). The advantage of these targets is that they can be auto-detected by the software, which benefits in time and accuracy.

Photogrammetry and rectified photography is used to improve the efficiency and the accuracy of the output. On the one hand, photogrammetric techniques and rectified photography can be employed for elements that are difficult to survey by Total Station. Moreover, experiences have shown that - in the case of 
complex features like floor constructions - an orthophoto or rectified photo is often more accurate and captures more information than a total station. Due to its indirect nature, photogrammetry is also less time consuming on site.

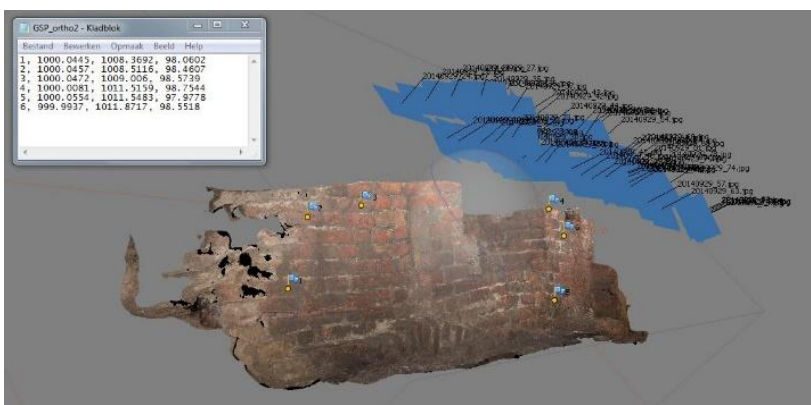

Figure 6. Brick wall dated circa 1250. Modelled with

Photoscan, scaled and referenced using coordinates measured with a total station. (Breestraat 90, Leiden)

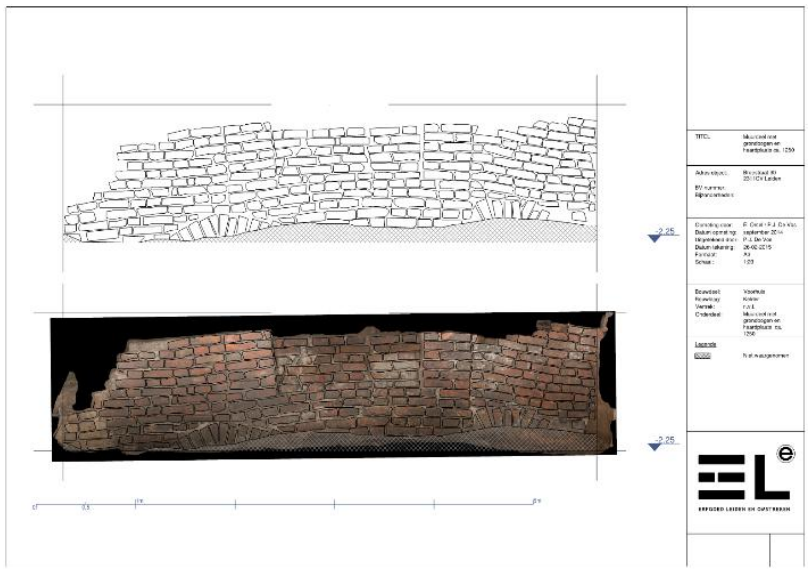

Figure 7. Brick wall dated circa 1250. Orthophoto traced in BricsCAD to amplify key details. (Breestraat 90, Leiden)

The rooms recorded with photogrammetry are captured using full frame DSLR cameras (Nikon D610 equipped with a 18$35 \mathrm{~mm}$ wide angle lens and Nikon D90 with a fixed $40 \mathrm{~mm}$ ). Photos are taken according to the photogrammetric rule $(3 \times 3)$ as established by CIPA (Waldhäusl e.a., 2013), using photogrammetric strips with $60-80 \%$ of overlap. The photos are taken at an appropriate scale, in order to capture the details of the structure given that the drawing set produced is at 1:50 or 1 : 20 scale.

Simultaneously, details that cannot be captured by the line of sight equipment, like complex timber frame joinery are sketched, while details like (moulded) profiles from pillars or windows are measured by hand.

Back in the office all collected data is processed. The final drawing production is an amalgamation of data produced from survey, photogrammetry and hand measurements. BricsCAD serves as platform for integrating these different data.

The drawings produced in TheoLt are standardized and refined with hand measurements and photographs. The plans sections are often ready within an hour of return to the office. Drawing cross sections and elevations take about the same time, depending on the level of details. That is, without the tracing of scaled rectified photographs and orthophotos.
The photo series taken for creating photogrammetric models are inserted in the software (Agisoft Photoscan). The auto generated targets are automatically detected and manually connected to the proper coordinates from a imported text file. The model is generated over night using the batch processing function. After, the orthophotos are imported into CAD.

The advantage of using BricsCAD is its ability to read GeoTIFF files so that the orthophotos are referenced and scaled in the correct $\mathrm{x}$ and $\mathrm{y}$ coordinates. For the $\mathrm{z}$ coordinate the 2D orthophoto has no information. Details from the imported orthographic photos are traced to produce line drawings and/or provided with crucial building archaeological information collected in sketches and detailed hand drawings. Once the survey drawings are completed, the CAD-files easily allow to produce reconstruction drawings of previous historical phases etc.

\subsection{Advantages of using advanced recording techniques}

Since 2013, the building archaeologists of Erfgoed Leiden have been working with the above described methodology - a combination of traditional and advanced, and of direct and indirect recording techniques. The use of advanced recording techniques has proven to be crucial to work efficiently (fast and accurate). Where as in the past, due to limited on site time, only quick sketches were made to support a written report, today elaborated accurate drawings are produced.

Moreover, the raw data and the drawings are not only useful to support a written report, but also as conservation ex situ. The high degree of accuracy captures historical material and building tracks for posterity (1).

This does not mean however, that drawing by hand has become superfluous. In order to meet the specific information need, each method - whether direct or indirect - is strategically used. Based on time, money, equipment, training, knowledge, etc., a choice is made on setting up a systematic documentation strategy. The integrated data coming from a combination of a number of techniques, both direct and indirect, are key to efficiently (i.e. fast and accurate) obtain a complete survey.

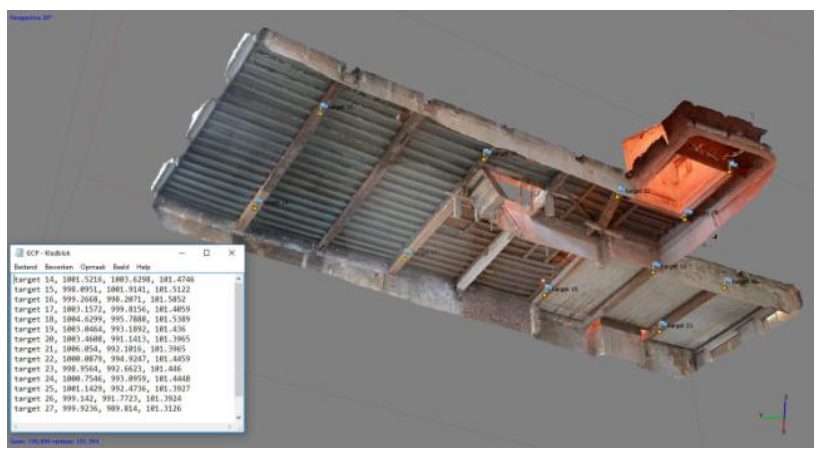

Figure 8. Floor construction dated 1630. Modelled with Photoscan, scaled and referenced using coordinates measured with a total station. (Breestraat 73, Leiden)

(1) These experiences in the city of Leiden share the conclusions of past research results, were similar methodologies proved to be successful for e.g. posterity recording of modern architecture in Mexico (Mezzino, 2015), and for emergency condition mapping in Morocco (Percy, 2015). 
Sketching for example works as an amplifier of key details that communicate important on site analyses. A sketch can also easily show details, like e.g. timber frame joinery, that are hard to see in photographs, or any other line-of-sight instrument. When it comes to documenting moulded profiles from pillars, windows etc., a drawing is easier produced by hand using rulers and a profile comb, than the effort spend deciphering the shape from a point cloud (Blake 2013).

The use of the Total Station to CAD setup leads to more accurate and precise data, and fastens time spent in the office constituting drawings.

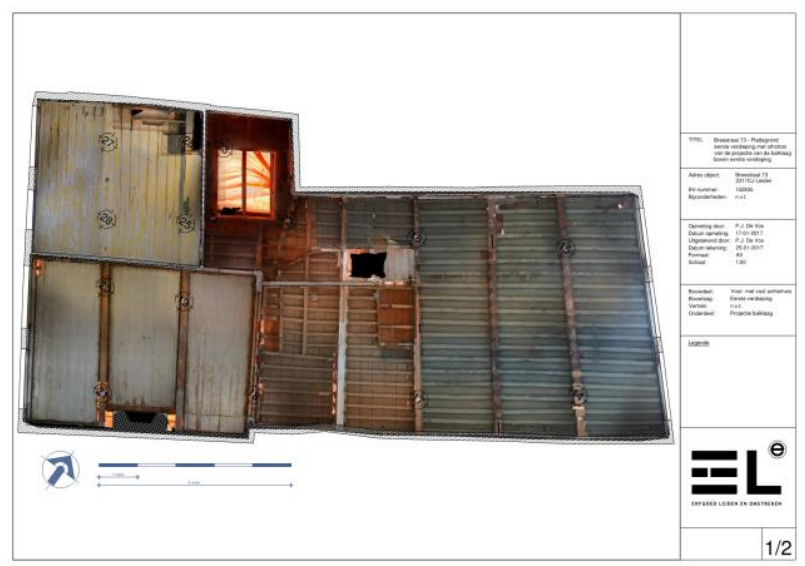

Figure 9. Orthophoto of floor construction, inserted in CAD.

Plan generated using a Total Station connected to a tablet with BricsCAD. (Breestraat 73, Leiden)

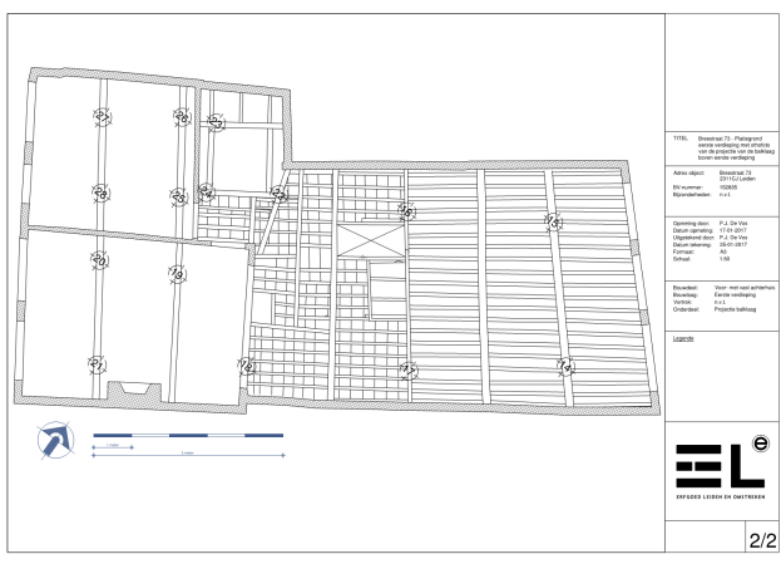

Figure 10. Floor construction, traced from orthophoto. Plan generated using a Total Station connected to a tablet with BricsCAD. (Breestraat 73, Leiden)

The use of scaled rectified photography and photogrammetry is a quick win to capture more data as these techniques do not only capture metric features but also record texture and colour. Moreover they do not require much of specialised training, and the cost is minimal when compared to a laser scan. Additional there is the fact that both techniques are very portable. Unlike a total station or a laser scanner, building archaeologists always carry a camera on site. This means that the basic equipment is already in place. Photogrammetric surveys do not have to be planned ahead and can be applied whenever necessary, even in emergency situations. In such conditions the Total Station is not being used for orientation and scaling, but simple measurements and scale bars are deployed.

Most importantly for building archaeology is that the use of scaled rectified photography and photogrammetry dramatically decreases time spent on site. The time won is used to uncover, analyse and interpret historical data.

\section{CONCLUDING REMARKS}

Heritage all around the world is constantly at risk. Even in the Netherlands, that knows a thorough monument regulation and active protection program, built heritage is under the constant threat of ongoing urban developments.

In the midst of construction works, building archaeologists are challenged to rapidly and accurately obtain a complete documentation. In Leiden, the use of advanced recording techniques as a supplement to traditional methods has proven to be crucial to meet these objectives.

However to promote and facilitate the use of new recording techniques within the field of building archaeology, challenges need to be overcome. As the invitation to the CIPA symposium in Ottawa states: "With new opportunities, there are also conflicts, and an intense effort to incorporate digital media into the education of conservation professionals" (CIPA, 2016).

Within the field of building archaeology, one-sided ideas on documentation are still advocated and educated. A strong case is made for hand drawing, as it forces close observation and physical contact. It is therefore considered the only method that allows critical observations. Traditionally hand drawing is not just seen as a means of capturing historical objects, but rather as means of understanding them. It is a building archaeological research method rather than a recording method.

In order to introduce advanced recording techniques into building archaeology, the challenge is to firstly convince the field that the effectiveness of any recording method is dependent on whether it meets a specific information need, and that is not dependent on the method as such. Secondly, the challenge lies in convincing educational institutions to embraces other types of recording techniques and not singling out hand drawing.

It is important to train both senior as junior building archaeologist in getting acquainted with advanced documentation techniques. After all, when documenting, a wellbalanced choice must be made based on time, money, equipment. Strategic use of both direct and indirect techniques will lead to efficient and as thorough as possible surveying, having a detailed as well as a rapid survey. Demonstrating the basics of the total station, photogrammetry and laser scanning can result in a more open-minded approach to what these techniques have to offer: quick, efficient, detailed and complete documentation of built heritage that is available and useful for posterity.

\section{ACKNOWLEDGEMENTS}

My special thanks go Andreas Georgopoulos, Geert Verhoeven, José Luis Lerma Garcia and Bill Blake for their efforts during the Masterclass 'Digital recording techniques for building 
archaeology', organized June $23^{\text {th }}-24^{\text {th }} 2016$ by Erfgoed Leiden for Dutch building archaeologists.

\section{REFERENCES}

Adams, A.T., 2016. Drawing for Understanding, Historic England, https://historicengland.org.uk/imagesbooks/publications/drawing-for-understanding/ (12 Feb. 2017).

Araoz, G., 2010. Heritage at Risk ICOMOS world report 20082010 on monuments and sites in danger, "foreword", C. Machat, M. Petzet, J. Ziesemer (eds.), Berlin, Germany http://www.icomos.org/risk/world_report/2008-

2010/H@R_2008-2010_final.pdf (31 Jan. 2017).

Blake, B., 2013. "Dawn of the photogrammetric age", Cambridge,

https://billboyheritagesurvey.wordpress.com/2013/12/26/archdo c-2013-dawn-of-the-new-photogrammetric-age/ (31 Jan. 2017).

Blake, B., 2016. "Drawing for understanding, some thoughts from someone who does", https://billboyheritagesurvey.wordpress.com/2016/12/13/drawin g-for-understanding-some-thoughts-from-one-who-does Jan. 2017).

Boato, A. \& Pittaluga, D., 2000. 15th World Conference on Non-Destructive Testing 15-21 October 2000 in Rome Conservation and Restoration in Art and Architecture "Building Archaeology: A Non-Destructive Archaeology" http://www.ndt.net/article/wcndt00/papers/idn365/idn365.htm (31 Jan. 2017).

CIPA, 2016. "Invitation to Digital Workflows for Heritage Conservation August 28 - September 1, 2017, Ottawa, Canada", http://www.cipaottawa.org/about-2 (24 May 2017).

ICOMOS, 1964. The Venice Charter, 2nd International Congress of Architects and Technicians of Historic Monuments, Venice.

ICOMOS, 1996. Principles for the recording of monuments, groups of buildings and sites. 11th ICOMOS General Assembly, Sofia.

Letellier R., Schmid W. \& LeBlanc F., 2007. Recording, Documentation, and Information Management for the Conservation of Heritage Places. The Getty Conservation Institute, Los Angeles.

Marlet, G. \& Van Woerkens, C., 2015. Atlas voor gemeenten, de waarde van Erfgoed, VOC Uitgevers, Nijmegen.

Marlet, G., 2016a. De opkomst van de oude stad, TPEdigitaal, 10(2), pp.75-88.

Mezzino D., Pei, W., Santana Quintero, M., Reyes Rodríguez, R., 2015. Documenting modern Mexican architectural heritage for posterity: Barragán's Casa Cristo, in Guadalajara, Mexico. ISPRS Annals of the Photogrammetry, Remote Sensing and Spatial Information Sciences, Volume II-5/W3, 2015 25th International CIPA Symposium 2015, 31 August - 04 September 2015, Taipei, Taiwan, pp. 199-206.

Percy, K. et al., 2015. Documentation for emergency condition mapping of decorated historic surfaces at the Caid Residence, The Kasbah Of Taourirt (Ouarzazate, Morocco). ISPRS Annals of the Photogrammetry, Remote Sensing and Spatial Information Sciences, Volume II-5/W3, 2015 25th International CIPA Symposium 2015, 31 August - 04 September 2015, Taipei, Taiwan, pp. 13-19.

RecorDIM task groups, 2007. "Metric Survey for Heritage Documentation. documentation for conservation, a manual for teaching metric survey skills", http://www.billblake.co.uk/files/Download/CIPA\%20Recordim\%20Teaching\% 20Guide.pdf (31 Jan. 2017).

Schuller, M., 2002. Building Archaeology, ICOMOS VII, Lipp $\mathrm{GmbH}$, München, p. 11.

Stenvert, R. \& Van Tussenbroek, G., 2015. Inleiding in de bouwhistorie. Opmeten en onderzoeken van oude gebouwen, Uitgeverij Matrijs, Utrecht, pp. 16-40.

Tung, A.M., 2001. Preserving the world's great cities: The destruction and renewal of the historic metropolis, Clarkson Potter, New York.

Waldhäusl, P., Ogleby, C. L., Lerma, J. L. \& Georgopoulos, A. 2013. "3 33 rules for simple photogrammetric documentation of architecture", http://cipa.icomos.org/wpcontent/uploads/2017/02/CIPA_3x3_rules_20131018.pdf (14 Feb. 2017). 